\title{
The accuracy of gestational age predicted from femur and humerus length in Saanen goats using ultrasonography
}

\author{
Mohamed Abdelghafar Rihab ${ }^{1}$, Hussein Ahmed Bushra², Mohamed Abdelrahim Salah ${ }^{3}$ \\ Tagelddin Ibrahim Mohamed ${ }^{4}$ \\ ${ }^{1}$ Sudan University of Science and Technology (SUST), College of Veterinary Medicine, \\ Department of Clinical Studies, Khartoum North, Sudan \\ ${ }^{2}$ National Ribat University, Institute of Radiotherapy and Nuclear Medicine, Khartoum, Sudan \\ ${ }^{3}$ Ribat Teaching Hospital, Khartoum, Sudan \\ ${ }^{4}$ Sudan University of Science and Technology, College of Science and Technology of Animal Production, \\ Khartoum North, Sudan \\ Received September 17, 2010 \\ Accepted May 16, 2012
}

\begin{abstract}
Serial transabdominal ultrasonographic scanning was performed to measure femur and humerus length of foetuses of Saanen goats to establish their gestational stage. Data were obtained from 38 goats that became pregnant after artificial insemination. Animals were restrained in a supine position on a special table designed for this purpose. Humerus and femur length were measured at weekly intervals starting from week 8 of gestation till the end of gestation. Real-time ultrasound scanner equipped with switchable frequency $(5-7.5 \mathrm{MHz})$ micro convex probe was used in the present study. Humerus and femur length showed strong positive correlation with gestational age $\left(\mathrm{r}^{2}=0.95\right)$. Measurements of humerus and femur of foetuses are useful indicators to predict gestational age at the $2^{\text {nd }}$ and $3^{\text {rd }}$ trimesters in Saanen goats. Measuring of only one bone length is quite enough. Incorporating of both measurements within a multiple regression equation did not improve predictive capacity of the bones. The results of the study were used to construct reference charts and gestational equations in Saanen goats utilizing humerus and femur measurements. In Sudan, this is the first study utilizing measurements of the femur and humerus and the first study comparing the length of the humerus and femur for predicting gestational age in Saanen goats.
\end{abstract}

Foetal bones, foetal development, ultrasound, caprine

Ultrasound has a widespread application in obstetrics and gynaecology including estimation of the stage of pregnancy and foetal weight (Greenwood et al. 2002). When the date of mating is unknown, the monitoring of foetal development allows estimation of gestational age which is important for appropriate prenatal management (Karen 2003; Lee et al. 2005) and would be useful to dry off lactating females at adequate period and to monitor females near term (Karen et al. 2001). The first pregnancy diagnosis in goats by ultrasonography was reported in 1983 (Hesselink and Taverne 1994). Since that time, diagnosis of pregnancy in small ruminants by transabdominal real-time ultrasound has become wide-spread (Haibel et al. 1989). Azevedo et al. (2007) reported that femur length is used to determine foetal age in human medicine. In veterinary medicine, only few articles have reported measurements of femur length in domestic goats. Karen et al. (2009) measured femur length in the Egyptian native breed of goats. In Sudan, there are only few studies concerning ultrasonography in goats (Abdelghafar et al. 2007a, b; Abdelghafar et al. 2009; Ahmed et al. 2010; Abdelghafar 2010; Abdelghafar et al. 2010).

The aim of the present study was to design reference charts and describe gestational equations for foetal femur and humerus during the $2^{\text {nd }}$ and $3^{\text {rd }}$ trimesters utilizing ultrasonography and to compare the accuracy of each bone measurements for prediction of gestational age in Saanen goats.

Address for correspondence:

Rihab Mohamed Abdelghafar Osman, B. V. Sc., M.Sc.

Department of Clinical Studies, College of Veterinary Medicine

Sudan University of Science and Technology (SUST)

P. O. Box 204, Hilat Kuku, Khartoum North, Sudan 


\section{Materials and Methods}

Animals

All procedures of the experimental work were performed with the approval of the General Directorate of Animal Wealth, Ministry of Agriculture, Animal Wealth and Irrigation, Khartoum State.

Thirty-eight Saanen goats with confirmed pregnancy, aged between 1-5 years and weighing 29-60 kg were used in the study. Oestrus was carefully observed by introducing a teaser buck twice a day. A goat showing oestrus signs was immediately inseminated using fresh semen collected from a proven fertile buck. Thus the day of introducing the buck was designated as day 0 of gestation.

Animals were fed Alfa-alfa hay ad libitum with a mixture of sesame cake, groundnut cake, sorghum and wheat bran as concentrate ration at the amount of $0.5 \mathrm{~kg}$ /day/animal with free access to water and mineral blocks supplement. The study was carried out from November 2008 to April 2009. Animals were kept and managed at Khartoum Livestock Genetics Improvement Center, Ministry of Agriculture, Animal Wealth and Irrigation, Khartoum State.

Animals were kept off food for $12 \mathrm{~h}$ prior to scanning. The ventral abdomen was clipped and shaved carefully using manual clippers. Animals were put in a supine position on a special table designed for this purpose (Abdelghafar 2006). Sufficient amount of ultrasonic gel (Sono gel Vertriebs GMBH, Germany) was applied to the area prior to scanning.

Ultrasound scanning

Real-time ultrasound machine (Pie medical, Easote, Holland) equipped with switchable frequency 5-7.5 MHz micro convex probe was used in the present study. Images were stored in a memory card attached to the scanner and later were printed on thermal paper, Sony corporation, type 1 (Normal), UPP-110S, 1-7-1, Konan, Minato$\mathrm{KU}$, Tokyo, Japan) using a video graphic printer UP-895EC (Sony, Japan). All the animals maintained good condition throughout the study.

Humerus and femur length

Humerus (Plate III, Fig. 1) was identified when the heart and scapula of the foetus were demonstrated. Femur (Plate III, Fig. 2) was confirmed by identifying the urinary bladder of the foetus. Humerus and femur measurements were done weekly starting at week 8 till the parturition; the lengths of the bones were measured according to the zones of intensive calcification which appeared echo-rich (Kahn 2004).

The weekly measurements for each bone were replicated 2-3 times when possible and the mean values were used for regression analysis.

\section{Statistics}

The relationship between gestational age and each of the fetal bone measurement was plotted as linear regressions and expressed as simple regression equations using Statistical Packages for Social Sciences (SPSS Inc. USA) version 16. The measurements of foetal bones were considered as being independent (x), while the gestational age $(\mathrm{y})$ being the dependent variable. A $P$ value of $\leq 0.05$ was considered significant. Plotting residuals against observed gestational age supported the

Table 1. Mean weekly measurements of the humerus and femur of Saanen goats

\begin{tabular}{ccc}
\hline Gestational age (weeks) & Humerus length $(\mathrm{cm})$ & Femur length $(\mathrm{cm})$ \\
\hline 8 & $0.8 \pm 0.1$ & $0.9 \pm 0.1$ \\
9 & $0.9 \pm 0.2$ & $1.0 \pm 0.2$ \\
10 & $1.2 \pm 0.1$ & $1.3 \pm 0.2$ \\
11 & $1.6 \pm 0.2$ & $1.7 \pm 0.2$ \\
12 & $1.9 \pm 0.2$ & $2.0 \pm 0.2$ \\
13 & $2.3 \pm 0.3$ & $2.5 \pm 0.2$ \\
14 & $2.8 \pm 0.3$ & $3.0 \pm 0.3$ \\
15 & $3.4 \pm 0.3$ & $3.4 \pm 0.3$ \\
16 & $4.0 \pm 0.3$ & $4.1 \pm 0.4$ \\
17 & $4.5 \pm 0.4$ & $4.6 \pm 0.4$ \\
18 & $5.1 \pm 0.5$ & $5.2 \pm 0.5$ \\
19 & $5.6 \pm 0.4$ & $5.9 \pm 0.6$ \\
20 & $6.2 \pm 0.6$ & $6.4 \pm 0.6$ \\
21 & $6.6 \pm 0.5$ & $6.7 \pm 0.5$ \\
22 & $6.8 \pm 0.7$ & $7.1 \pm 0.7$ \\
23 & 7 & 7.2 \\
\hline
\end{tabular}
linear relationship between each of the two variables and gestational age.

\section{Results}

The average gestational length for 38 goats in the present study was found to be $146 \pm 12$ days. Weekly measurements of the humerus and femur are demonstrated in Table 1. Measurements of the femur and the humerus were highly significantly $(P<0.0001)$ correlated with gestational age $\left(r^{2}=0.95\right)$. The two measurements showed the same high correlation with gestational age. Data obtained from these measurements were plotted against gestational age and a regression line was fitted to the scatter plot (Figs 3, 4). Regression 


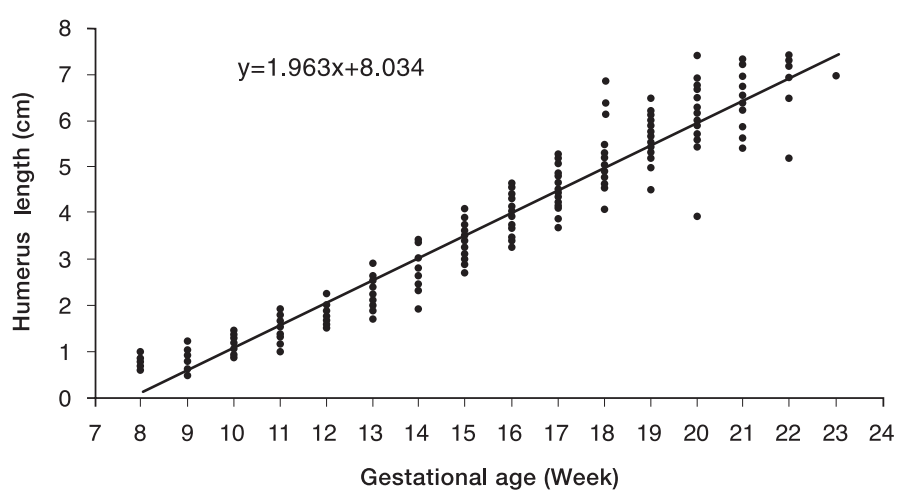

Fig. 3. Scatter plot shows the relationship between the humerus length $(\mathrm{cm})$ and gestational age (weeks) in Saanen goats.

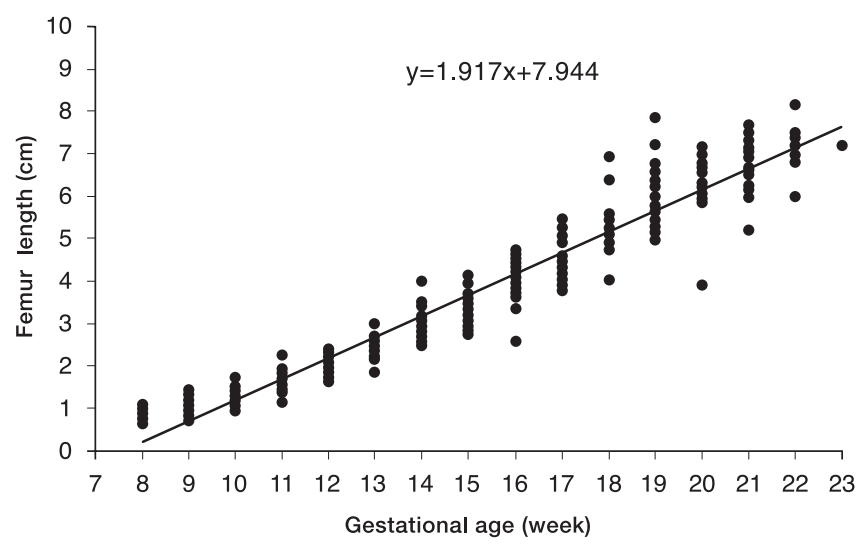

Fig. 4. Scatter plot shows the relationship between the femur length $(\mathrm{cm})$ and gestational age (weeks) in Saanen goats.

equations, $P$-values and correlation coefficient $\left(\mathrm{r}^{2}\right)$ between measurements and gestational age were calculated. A gestational equation for femur was described as follows: $\mathrm{y}=1.917 \mathrm{x}$ +7.944 and for humerus: $y=1.963 \mathrm{x}+8.034$, where $\mathrm{y}$ is being the gestational age (week) and $\mathrm{x}$ is the foetal parameter $(\mathrm{cm})$.

$P$ value for both humerus and femur is $P<0.0001, \mathrm{r}^{2}$ for both is $95 \% ; \mathrm{r}^{2}=$ correlation coefficient, $\mathrm{y}=$ gestational age (weeks), $\mathrm{x}=$ foetal measurements $(\mathrm{cm})$.

\section{Discussion}

To the best of the authors' knowledge this is the first study to compare the accuracy of humerus and femur length for prediction of gestational age in goats.

The present study demonstrated that the humerus was measurable at 50 days of gestation. Suguna et al. (2008) reported that the bony structures of the goat foetuses were detectable on Day 56 of gestation, while Soroori et al. (2001) reported that the humerus was first diagnosed and measured at 82 days of gestation in Iranian sheep foetuses. 
In the present study, the humerus showed highly significant correlation $(P<00001$, $\left.\mathrm{r}^{2}=0.95\right)$ with gestational age. Vural et al. (2008) measured the humerus length between 37-130 days post breeding in Akkaraman ewes and reported correlation coefficient of $\mathrm{r}^{2}=0.92$.

Increased accuracy in the present study compared to the previous one could be due to the fact that in our study the measurements were done at 50 days of gestation when the humerus was easily and accurately measurable, whereas in the previous study, the humerus was measured earlier at 37 days of gestation. Breed differences could also be a factor for these differences. Due to lack of information in the literature regarding the humerus length in goats, no other comparisons could be done.

The femur length has been commonly used to predict gestational age in human pregnancies (Bulnadra et al. 2004; Dare et al. 2004; Isobe 2004); however, the measurement in veterinary medicine is limited. Accurate estimation of gestational age has been established in domestic sheep (Noia et al. 2002) and wild sheep (Santiago-Moreno et al. 2005) using measurements of the femur. In the present study the femur length was measurable at 50 days post breeding. Gonzalez-Bulnes et al. (1998) reported that the femur was easily identifiable and measurable at 61 days of gestation in ewes; while Place et al. (2002) reported that the measurements of the femur could be done at 65 days post breeding in spotted hyenas.

The relationship between the femur length and gestational age was obtained. The femur length showed highly significant correlation $\left(P<0.0001 ; \mathrm{r}^{2}=0.95\right)$ with gestational age. Slightly lower correlation compared to our study $\left(r^{2}=0.93\right)$ was reported by Diana et al. (2007) in Serrana goats between 47-82 days of gestation. Also Karen et al. (2009) reported correlation coefficient of $\mathrm{r}^{2}=0.90$ between 55-125 days of gestation in Egyptian Balady goats. Lower correlations compared to the present study were reported by many authors. Santiago-Moreno et al. (2005) found a correlation coefficient of $r^{2}=0.89$ in the European mouflon between 38-114 days post breeding, while Vural et al. (2008) obtained correlation coefficient of $\mathrm{r}^{2}=0.79$ between 37-115 days of gestation in Akkaraman ewes. Gonzalez-Bulnes et al. (1998) reported correlation coefficient of $r^{2}=0.61$ between 61-90 days post breeding in Manchega dairy ewes. High correlation in the present study compared to the previous ones could be due to that in this study the measurements of the femur extended till the end of parturition in which the femur length has been considered a more reliable index for prediction of gestational age in late gestation (Place et al. 2002). In the previous studies the measurements of the femur were ended in the $2^{\text {nd }}$ trimester or early $3^{\text {rd }}$ trimester and/or the measurements were performed earlier at 37 and 38 days in which Santiag o-Moreno et al. (2005) reported that the femur may be observed at a more precocious stage (38 days); however, it was not easy to measure until the second third of gestation. Breed differences could also be a factor for these differences.

We can recommend ultrasonography as a non-invasive, non-time consuming and efficient tool for predicting gestational age in Saanen goats. Putting the animal in dorsal recumbancy on a specially designed table is highly recommended.

\section{Acknowledgement}

Great thanks are due to the Ministry of Agriculture, Animal Wealth and Irrigation, Khartoum State for providing the experimental animals. The Sudan University of Science and Technology is greatly acknowledged. Great thanks belong to prof. Abdelhamid Ahmed Alfadil, prof. Shadia Abd Atti Omer and prof. Hassan Ahmed Ali for their valuable recommendations and comments.

\section{References}

Abdelghafar RM 2006: Pregnancy diagnosis and fetometry in Saanen goats using real-time ultrasonography. M. Sc. thesis, Sudan University of Science and Technology. 71p 
Abdelghafar RM 2010: Ultrasonography as a diagnostic tool for fetal mortality in goats (Capra hircus) in the Sudan (two case reports). Assiut Vet Med J 56: 316-322

Abdelghafar RM, Abdallah SA, Ahmed BH 2009: Pregnancy diagnosis and fetal quantification in Damascus goats using transabdominal real-time ultrasonography. Assiut Vet Med J 55: 273-279

Abdelghafar RM, Ahmed BH, Bakheit AO 2007a: Crown rump length and bi parietal diameter to predict gestational age in Saanen goats. J Anim Vet Advances 6: 454-457

Abdelghafar RM, Bakheit AO, Ahmed BH 2007b: B-Mode real-time ultrasonography for pregnancy diagnosis and fetal numbers in Saanen goats. J Anim Vet Advances 6: 702-705

Abdelghafar RM, Ibrahim MT, Abdelrahim SM, Ahmed BH 2010: Sensitivity and specificity of real-time ultrasonography for pregnancy diagnosis and litter size determination in Saanen goats (Capra hircus). 14 ${ }^{\text {th }}$ Sci Cong Fac Vet Med, Assiut Univ Egypt.

Ahmed BH, Hamad RJ, Abdelghafar RM 2010: Ultrasonography for diagnosis of hydrometra and pyometra (two case reports). Assiut Vet Med J 56: 225-229

Azevedo E, Aguiar filho C, Freitas Neto L, Robelo M, Santos M, Lima P, Freitas V, Oliveira M 2007: Ultrasound fetal measurement parameters for early estimate of gestational age and birth weight in ewe. Med Vet 1: 56-61

Bulandra AM, Kuczera M, Machnik BM, Kuczera J, Gieleeki JS 2004: Is manual foot length measurement of comparable value to ultrasound femur and humerus measurement in anatomical studies for the assessment of fetal age? Folia Morphol 63: 203-207

Dare FO, Smith NC, Smith P 2004: Ultrasonic measurement of bi parietal diameter and femur in fetal age determination. West Afr J Med 23: 24-26

Gonzalez-Bulnes A, Santiago-Moreno A, Lopez-Sebastian A 1998: Estimation of fetal development in Manchega dairy ewes by transrectal ultrasonographic measurements. Sm Rumin Res 27: 243-250

Greenwood P, Slepetis R, Mcphee M, Bell A 2002: Prediction of stage of pregnancy in prolific sheep using ultrasound measurement of fetal bones. J Reprod Fertil Dev 14: 7-13

Haibel G, Perkins N, Lidl G 1989: Breed differences in bi parietal diameters of second trimester Toggenburg, Nubian and Angora goat fetuses. Theriogenology 32: 827-833

Hesselink J, Taverne M 1994: Ultrasonography of the uterus of the goat. Vet Q 16: 41-45

Isobe T 2004: Approach for estimating fetal body weight using two- dimensional ultrasound. J Matern Fetal Neonatal Med 15: 225-231

Kahn W 2004: Veterinary reproductive ultrasonography. Schlutersche Verlagsgesellschaft, mbH and CO. KG, Hans-Bockler-Allee 7, 30173 Hannover, Germany

Karen A, Kovacs P, Beckers J, Szenci O 2001: Pregnancy diagnosis in sheep: review of the most practical methods. Acta Vet Brno 70: 115-126

Karen AM 2003: Pregnancy diagnosis in sheep. Doctoral thesis, Szent Istvan University

Karen AM, Elsayed F, Saber AS 2009: Estimation of gestational age in Egyptian native goats by ultrasonographic fetometry. Anim Reprod Sci 114: 167-174

Lee Y, Lee O, Cho J, Shin H, Choy, Shim Y, Choi W, Shin H, Lee D, Lee G, Shin S 2005: Ultrasonic measurements of fetal parameters for estimation of gestational age in Korean Black Goats. J Vet Med Sci 67: 497-502

Noia G, Romano GM, Terzano M, Dc Santis M, Di Domenico A, Cavalicre M, Ligato S, Petrone A, Fortunato G, Filippetti F, Caruso A, Mancuso S 2002: Ovine fetal growth curves in twin pregnancy: ultrasonographic assessment. Clin Exp Obstet Gynecol 29: 251-256

Place NJ, Weldele ML, Wahaj SA 2002: Ultrasonic measurements of second and third trimester fetuses to predict gestational age and date of parturition in captive and wild Spotted Hyenas (Crocuta crocuta). Theriogenology 58: $1047-1055$

Santiago-Moreno J, Gonzalez-Bulnes A, Gomez-Brunet A, Toledano-Diaz A, Lopez-Sebastian A 2005: Prediction of gestational age by transrectal ultrasonographic measurements in the Mouflon (Ovis gmelini musimon). J Zoo Wild Med 36: 457-462

Soroori S, Parviz T, Abbas V 2001: Chall fetus pregnancy age determination by ultrasonography. Society for the study of reproduction (SSR). $34^{\text {th }}$ Annual meeting, University of Ottawa 

Plate III

Rihab M. A. et al.: The accuracy of... pp. 295-299

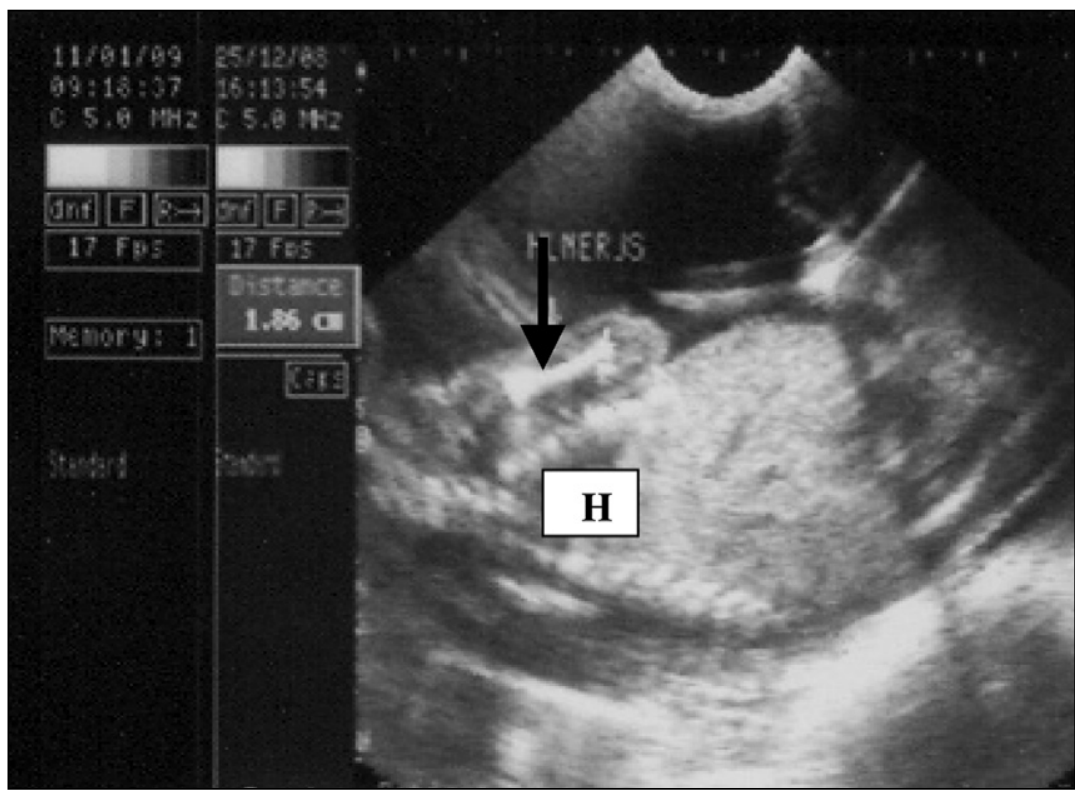

Fig. 1. Humerus of Saanen foetus at day 80 of gestation (Arrow)

$\mathrm{H}=$ heart

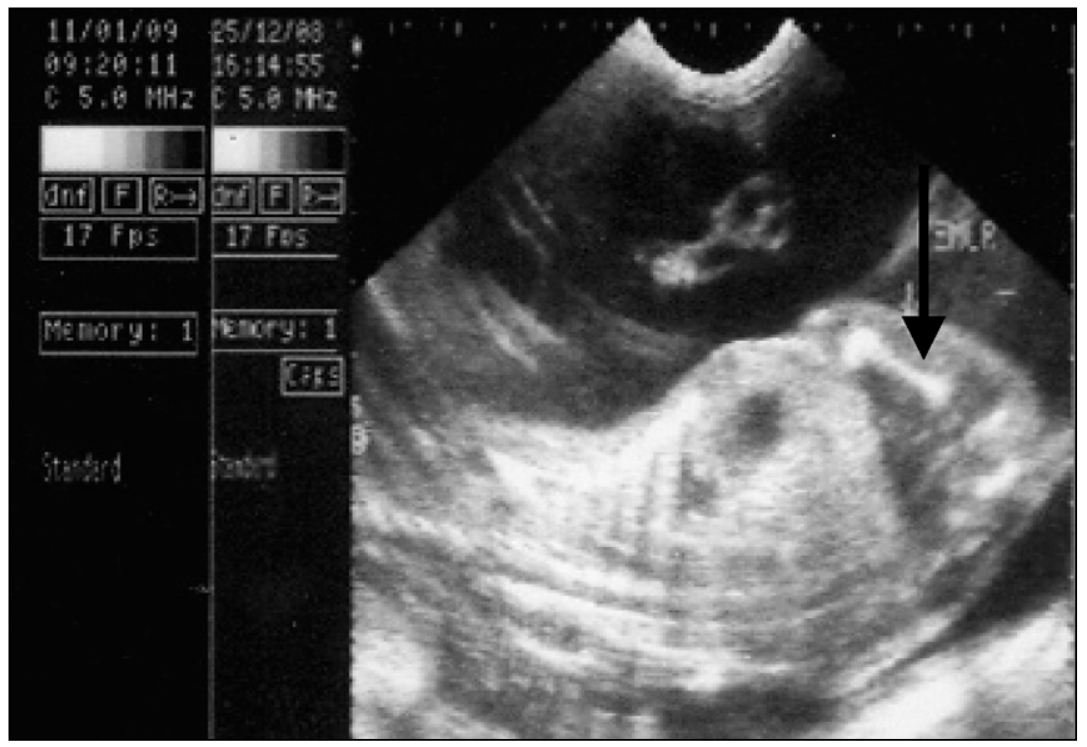

Fig. 2. Femur of Saanen foetus at day 80 of gestation (Arrow) 